\title{
Managing paediatric giant retinal tears
}

\author{
Rajiv Raman ${ }^{1} \cdot$ Rekha Priya Kalluri Bharat ${ }^{1} \cdot$ Pramod Bhende $^{1} \cdot$ Tarun Sharma $^{2}$
}

Received: 20 May 2021 / Revised: 21 May 2021 / Accepted: 26 May 2021 / Published online: 11 June 2021

(c) The Author(s), under exclusive licence to The Royal College of Ophthalmologists 2021

By definition, giant retinal tears (GRTs) are those tractional retinal breaks that extend circumferentially to at least three clock hours $\left(90^{\circ}\right)$ or more [1]. The retinal detachment associated with GRTs poses a great challenge even to a well experienced vitreoretinal surgeon. These challenges include posterior rolling of the edge of GRT, radial extension of one of the edges of GRT, vitreous haemorrhage, and proliferative vitreoretinopathy (PVR). However, several advances in instrumentation (small-gauze vitrectomy), visualization (wide-angle viewing systems), illumination (chandelier system) and manipulation of the detached retina (perfluorocarbon liquid, PFCL) have significantly contributed to improved surgical success.

Managing GRT-associated RDs in paediatric age group adds additional challenges: healthy and more tenacious vitreous gel, absence of PVD, strong vitreoretinal interface relationship, delayed presentation, associated ocular or systemic disease (High myopia or stickler syndrome), trauma related ocular co-morbidities such as cataract or subluxated lens or glaucoma, postoperative head positioning, and amblyopia therapy. In this issue, Hasan $\mathrm{N}$ and coauthors report the demography, clinical profile, and surgical outcome of paediatric GRT related retinal detachments in a large series of 91 eyes. They reported that $5.6 \%$ of the paediatric retinal detachments were due to GRTs, and onethird of them developed detachments in the fellow eyes. Two common risk factors for GRTs in children were high myopia and trauma. Though they achieved final anatomic success of $63.4 \%$ (single operation success, $40.2 \%$ ), recurrent retinal detachment occurred in nearly $60 \%$. Factors that contributed to increased success included absence of PVR

Rajiv Raman

rajivpgraman@gmail.com

1 Sri Bhagwan Mahavir Vitreoretinal services, Sankara Nethralaya, Chennai, India

2 Edward S. Harkness Eye Institute, Columbia University Medical Center, New York, NY, USA (or just PVR grade A) and presence of PVD. Visual success $(\geq 1 / 60)$ was achieved in $54.9 \%$ eyes.

In adult GRTs, vitreous changes-syneresis and liquefaction-occurs in the central or core vitreous gel, with formation of a large central lacuna. Later, peripheral gel gets condensed, and its posterior aspect forms an equatorially oriented transvitreal membrane, contraction of this membrane cause tearing of the retina along the posterior border of the vitreous base. In children, the vitreous syneresis and liquefaction is not seen. This is due to collagen type IX which coats the outer surface of collagen type II in the vitreous, preventing collagen fibrils from adhering to each other [2]. This may also be responsible for strongly adherent vitreoretinal interface. On the contrary, in hereditary vitreoretinopathies and pathological myopia there is vitreous liquefaction and fibrillar collagen condensation explaining the occurrence of GRTs in younger age [2]. Though Hasan et al. have reported that paediatric RD due to GRT is $5.6 \%$, few studies have reported a higher incidence of GRTs-associated retinal detachment (15-20\%) [3, 4]. While in adults the reported incidence of GRT-associated $\mathrm{RD}$ is lower $(0.5-8.3 \%)[5,6]$.

In children, both blunt (60\%) and penetrating injury $(40 \%)$ can result in GRT. Savastano et al. described case series of RD associated with GRT after blunt trauma with no PVD [7]. They postulated that the formation of a GRT is related to the presence of a weak peripheral retinal area on which there is an abnormal vitreous traction [7]. These weak areas may be due to the formation of retinal necrotic haemorrhagic areas that were a result of the antero-posterior force of the blunt trauma [7]. On the contrary, in a retinal dialysis, the retina is circumferentially separated from the pars plana at the ora serrata [8]. Unlike giant retinal breaks which is caused by vitreous traction, in a retinal dialysis the vitreous base is often attached to the retina posterior to the edge of the tear, but there can also be an avulsion of the vitreous base [8].

Vitreoretinal surgery in paediatric GRTs is somewhat challenging. Creation of a PVD often requires the use of intraocular forceps (or a pick) as the underlying retina is detached, so using just high aspiration or suction force might 
increase the risk of iatrogenic retina break, and this situation becomes more complex in eyes with Marfan syndrome or Stickler syndrome in view of abnormal vitreoretinal adhesions. Visualization of vitreous, posterior hyaloid and its attachment to detached retina can be enhanced using intravitreal Triamcinolone acetonide, and many times multiple reinjections might be needed [9, 10]. A bubble of PFCL can also be used to keep the detached retina down as the posterior hyaloid is being stripped away mechanically [11]. A meticulous removal of vitreous gel from the posterior edge of GRTs with complete excision of anterior edge minimize the risk of membrane proliferation along these edges [12]. It is important to pay special attention to the inferior horn of GRT that it is totally free from any residual gel or membrane. At times, an encircling element with a mild to moderate indentation is desirable to support GRTs; be mindful of the fact that a high buckle encourages posterior slippage or purse-string effect. If any bridging blood vessels is present, intraocular diathermy helps in haemostasis before severing it. In order to perform vitreous base excision $360^{\circ}$, occasionally even a clear lens needs to be removed to achieve surgical goals. The upper level of PFCL could be kept below the tip of infusion cannula so as to prevent multiple bubbles formation due to fluid currents [13]. A direct PFCL-Silicone oil exchange is encouraged to prevent posterior slippage of the edge of the GRT [13]. A higher viscosity silicone oil (5000 centistoke) is preferred in paediatric age group as it is difficult to maintain postoperative positioning and it is less likely to emulsify [14]. The silicone oil could be removed around 4-6 months later, and the procedure could be combined with additional steps like removal of any epiretinal or epimacular membrane, secondary IOL or endocyclophotocoagulation etc.

In general, children are also more prone to PVR than adults. In an eye with GRT, the risk of PVR increases as a large area of bare RPE cells is exposed to fluid currents and these cells can migrate, proliferate and form membrane on the surface of the retina as well as in the subretinal space [15]. Informing these risks to the family prior to surgery and sharing what is expected of in such clinical setting including long-term visual rehabilitation and amblyopia therapy will build the trust and relationship between the care provider team and the family.

Author contributions RR: Concept, initial draft. RPKB: Literature search. PB \& TS: Review.

\section{Compliance with ethical standards}

Conflict of interest RPKB, PB, and TS: None. RR: Is an editorial board member for Eye Journal.

Publisher's note Springer Nature remains neutral with regard to jurisdictional claims in published maps and institutional affiliations.

\section{References}

1. Schepens CL, Dobble JG, Mc MJ. Retinal detachments with giant breaks: preliminary report. Trans Am Acad Ophthalmol Otolaryngol Am Acad Ophthalmol Otolaryngol. 1962;66:471-9.

2. Bishop PN, Holmes DF, Kadler KE, McLeod D, Bos KJ. Agerelated changes on the surface of vitreous collagen fibrils. Invest Ophthalmol Vis Sci. 2004;45:1041-6.

3. Weinberg DV, Lyon AT, Greenwald MJ, Mets MB. Rhegmatogenous retinal detachments in children: risk factors and surgical outcomes. Ophthalmology. 2003;110:1708-13.

4. Gonzales CR, Singh S, Yu F, Kreiger AE, Gupta A, Schwartz SD. Pediatric rhegmatogenous retinal detachment: clinical features and surgical outcomes. Retina. 2008;28:847-52.

5. Chou S-C, Yang C-H, Lee C-H, Yang C-M, Ho T-C, Huang J-S, et al. Characteristics of primary rhegmatogenous retinal detachment in Taiwan. Eye 2007;21:1056-61.

6. Yorston DB, Wood ML, Gilbert C. Retinal detachment in East Africa. Ophthalmology. 2002;109:2279e83.

7. Savastano A, Barca F, Tartaro R, Caporossi T, Rizzo S. Posttraumatic giant retinal tear without posterior vitreous detachment: a case series. Ophthalmic Surg Lasers Imaging Retin. 2018;49:686-90. https://doi.org/10.3928/23258160-20180831-06. PMID: 30222803.

8. Smiddy WE, Green WR. Retinal dialysis: pathology and pathogenesis. Retina 1982;2:94-116.

9. Couch SM, Bakri SJ. "Use of triamcinolone during vitrectomy surgery to visualize membranes and vitreous. Clin Ophthalmol. 2008;2(no. 4):891-6.

10. Enaida H, Hata Y, Ueno A, Nakamura T, Hisatomi T, Miyazaki $\mathrm{M}$, et al. Possible benefits of triamcinolone-assisted pars plana vitrectomy for retinal diseases. Retina. 2003;23:764-70.

11. Ambresin A, Wolfensberger TJ, Bovey EH. Management of giant retinal tears with vitrectomy, internal tamponade, and peripheral $360^{\circ}$ retinal photocoagulation. Retina. 2003;23:622-8.

12. Wenick AS, Barañano DE. Evaluation and management of pediatric rhegmatogenous retinal detachment. Saudi J Ophthalmol. 2012;26:255-63.

13. Berrocal MH, Chenworth ML, Acaba LA. Management of giant retinal tear detachments. J Ophthalmic Vis Res. 2017;12:93-97. https://doi.org/10.4103/2008-322X.200158.

14. Heimann H, Stappler T, Wong D. Heavy tamponade 1: a review of indications, use, and complications. Eye. 2008;22:1342-59.

15. Shunmugam M, Ang GS, Lois N. Giant retinal tears. Surv Ophthalmol. 2014;59:192-216. 